\title{
¿Existe una iglesia del Vaticano II?
}

\author{
Does a Vatican I/ church exist?
}

Fernando López Arias · Istituto di Liturgia. Pontificia Università della Santa Croce (Roma)

https://doi.org/10.17979/aarc.2015.4.0.5122

\section{RESUMEN}

En los últimos cincuenta años ha habido un cambio notable en la forma del templo católico respecto a las décadas precedentes. Se considera habitualmente que dicha evolución se debe al Concilio Vaticano Il: la renovación del espacio litúrgico cristiano sería una de sus consecuencias visibles más evidentes. Sin embargo, el Concilio habló muy poco sobre arquitectura litúrgica y, desde luego, no pretendió dar directrices concretas sobre el modo de construir iglesias. El análisis de los textos conciliares muestran que la iglesia del Concilio Vaticano /l es un lugar de oración, entendiendo oración como un modo general de denominar un amplio programa de usos. La funcionalidad litúrgica y el fomento de la participación activa de los fieles son dos criterios generales que el Concilio deseó para la renovación de la arquitectura cristiana. Esta debería haberse llevado a cabo al mismo tiempo que la reforma de los libros de la liturgia renovada.

\section{PALABRAS CLAVE}

Movimiento litúrgico, arquitectura sagrada contemporánea, Commissio preparatoria, Concilio Vaticano II, Sacrosanctum Concilium.

\section{ABSTRACT}

In the last 50 years there has been a remarkable change in the shape of the Catholic Church building with regard to the preceding decades. It is usually considered that this evolution is due to the Second Vatican Council: the renewal of the Christian liturgical space would be one of its most visible consequences. However, the Council said little about liturgical architecture and certainly did not intend to give specific guidelines on how to build churches. The analysis of the conciliar texts show that a Vatican II church is a place of prayer, with the understanding of prayer as as a general way of denominating a broad program of usage. The two main criteria that the Council desired in the renewal of Cristian architecture were: liturgical functionality and the promotion of active participation by the faithful. This should have been realised at the same time as the reform of the books of the renewed liturgy.

\section{KEYWORDS}

Liturgical Movement, Contemporary Sacred Architecture, Preparatory Commissio, Vatican II, Sacrosanctum Concilium. 


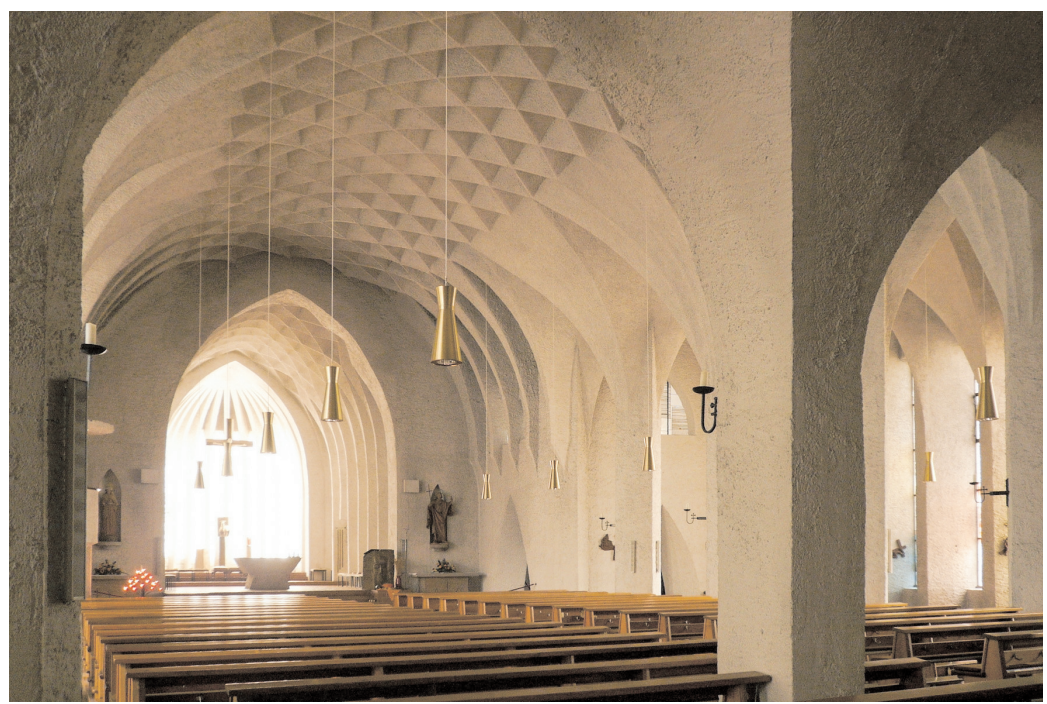

Fig. 01. Dominikus Böhm, Iglesia de San Juan Bautista, Neu-Ulm (Alemania), 1921/1927.

\section{UNA APARENTE PARADOJA}

«Para la persona corriente que frecuenta la Iglesia hay dos cosas que aparecen como los resultados más tangibles de la reforma litúrgica del Concilio Vaticano II: la desaparición de la lengua latina y el giro de los altares hacia el pueblo. Quien lee los textos del Concilio mismo constatará con sorpresa que en las resoluciones del Concilio no se encuentran, de esta forma, ni una ni otra. [...] En el texto del Concilio no se habla del giro de los altares hacia pueblo; solo aparece en instrucciones post-conciliares» (Ratzinger 2012, 349).

Estas palabras de Joseph Ratzinger sirven bien como introducción a esta comunicación. En la percepción común de un gran número de personas, a partir del último concilio se han producido significativos y vastos cambios en la arquitectura sagrada. Es habitual hablar de la iglesia o la arquitectura según el Concilio Vaticano II. Algunos de dichos cambios han sido - de hecho- exigidos o sugeridos oficialmente por la misma Iglesia a través de sus comisiones, congregaciones o conferencias episcopales; otros, han sido realizados con el impulso del Movimiento Litúrgico del siglo XX. Sin embargo, aunque resulte asombroso, el Concilio Vaticano II se pronunció poco en sus documentos sobre cuestiones relativas a la arquitectura litúrgica. El objetivo de esta comunicación es mostrar la voluntad del Concilio sobre la arquitectura sagrada a través del análisis de estos escasos pero preciosos pasajes.

Al final del siglo XIX y el inicio del XX, el arte cristiano post-romántico sufría lo que Timothy Verdon ha denominado «agotamiento poético» $(2012,242)$. Tras la I Guerra Mundial asistimos a la singular sinergia entre teólogos y pastores influidos por el Movimiento Litúrgico y arquitectos y artistas del Movimiento Moderno, henchidos de deseos de renovación espiritual y estética. El inicio de la arquitectura sagrada moderna se suele situar en los años veinte: las iglesias de Notre Dame de Raincy, de Auguste Perret en París (1920/23); San Juan Bautista, de Dominikus Böhm en Neu-Ulm (1921/27); y la del Corpus Christi, de Rudolf Schwarz en Aquisgrán (1928/30) constituyen hitos en la historia de la renovación litúrgico-arquitectónica del templo cristiano.

Algunos elementos adquiridos o potenciados por la arquitectura cristiana del siglo XX -inspirados por el Movimiento Litúrgico - fueron el redescubrimiento arqueológico de las domus ecclesiae y las basílicas paleocristianas como paradigma funcional y estético para el espacio ritual; la puesta en valor de la dimensión comunitaria de la celebración, que se refleja en la estructura de la iglesia; la búsqueda de la unidad e integridad del aula litúrgica; la centralidad simbólica y la autonomía espacial del altar, etc. (Fig. 01). 
Fig 02 Los miembros de la Commissio preparatoria de la constitución litúrgica. En el centro de la imagen el cardenal Cicognani y a su izquierda Annibale Bugnini (a la derecha en la foto).

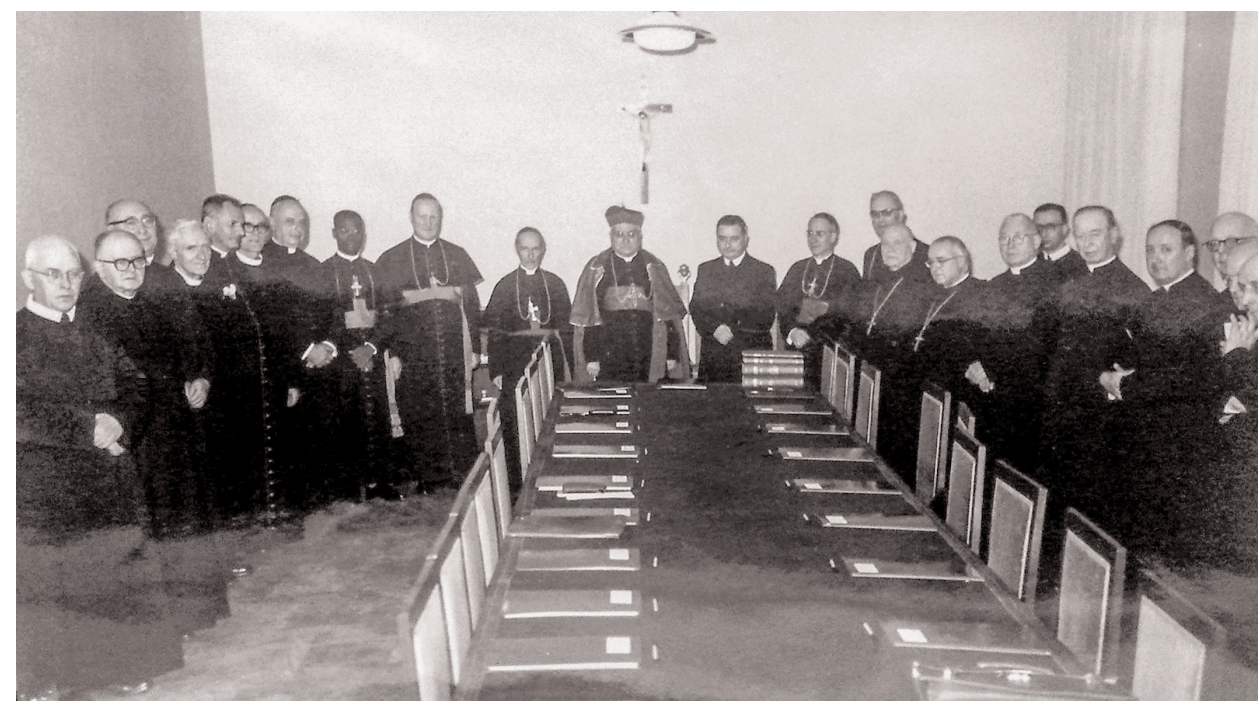

Un documento de singular importancia en este camino de renovación de la arquitectura sagrada apareció poco después de la II Guerra Mundial. La Conferencia de los obispos de Alemania, reunida en Fulda, emanó en 1947 unas Richtlinien für die Gestaltung des Gotteshauses aus dem Geiste der Römischen Liturgie (Directivas para la construcción de iglesias según el espíritu de la liturgia romana) (Plazaola 2006, 515-522). Estas normas regularon la construcción de centenares de iglesias en Alemania en el período de la posguerra, que han marcado notablemente la pauta de la arquitectura cristiana del período previo - y también posterior- al Concilio Vaticano II. El documento comienza exponiendo que el templo cristiano es «primero y sobre todo» el lugar de la celebración del sacrifico eucarístico, el lugar de la acción de culto sacerdotal del pueblo de Dios (I-1). La naturaleza de la iglesia cristiana es definida principalmente a través del principio de la acción celebrativa y, más concretamente, como espacio de celebración de la Eucaristía: este sería el «espíritu de la liturgia romana» (Plazaola 2006, 517).

\section{LA COMMISSIO PREPARATORIA SOBRE SAGRADA LITURGIA DEL CONCILIO VATICANO ॥}

En vista del concilio ecuménico convocado, Juan XXIII erigió en 1960 una Commissio preparatoria encargada de la redacción de un esquema de constitución litúrgica, presidida por el cardenal Gaetano Cicognani (1881/1962) y cuyo secretario era el sacerdote lazarista Annibale Bugnini (1912/82) (Fig. 02). El fruto del trabajo de la Commissio fue el borrador de la primera constitución conciliar: Sacrosanctum Concilium (en adelante SC), publicada el 3 de diciembre de 1963. Los componentes de la Commissio, divididos en secciones, prepararon - tras diversas redacciones - un esquema que posteriormente fue examinado, discutido y modificado por los Padres conciliares. A este borrador se adjuntaba un anexo que incluía las Declarationes. Estas eran notas a algunos puntos del borrador, en las que se detallaba su contenido o el sentido de sus palabras. Para nuestro estudio, es preciso que nos detengamos en la Declaratio que acompaña el punto 106 del borrador definitivo - que en la redacción final de SC será su punto 128 - que trata la reforma de la arquitectura sagrada.

Es interesante observar la cercanía entre las propuestas de las directivas alemanas sobre arquitectura litúrgica de 1947 y la Declaratio que acompaña a este punto. Pienso que dicha coincidencia se debe en buena medida a que el redactor de las directivas alemanas el profesor de historia y de arqueología cristiana de la Universidad de Bonn Theodor Klauser (1894/1984)-, formaba parte de la sección de la Commissio que redac- 
tó el capítulo VIII del borrador de la constitución litúrgica, junto a las Declarationes que lo acompañaban (Lameri 2013, 56). Dichos puntos constituirán la base para la redacción del capítulo VII de SC (122-130) sobre el arte sagrado.

La Declaratio en cuestión consta de catorce números. Estos abordan los siguientes temas:

1. La disposición de los espacios celebrativos en la iglesia surgida a partir de la asamblea, como repercusión y símbolo de ella.

2. El lugar destacado de la sede presidencial, tanto en las catedrales como en otros templos.

3. La posición del altar, como elemento autónomo separado de la pared y en medio de la asamblea: un centro más bien ideal que geométrico. Aunque la Declaratio dedica un punto concreto a la nave de los fieles $\left(n^{\circ} 9\right)$, no existe un tratamiento específico para el santuario o presbiterio, sino que se opta por exponer independientemente cada uno de sus elementos. Es más, al indicar que el altar se sitúa en un lugar intermedio entre el presbiterio y los fieles (loco intermedio inter presbyterium et plebem, idest: in medio synaxeos), la Declaratio parece sugerir que el altar se sitúa fuera del santuario (Lameri 2013, 825).

4. Los altares menores, construidos en capillas independientes, de modo que se perciba visiblemente la primacía del altar principal.

5. La reserva de la Eucaristía en el altar mayor o en otro menor, o bien en otro lugar de la iglesia.

6. La posibilidad de celebrar versus populum. La Declaratio en este punto indica consultar dos puntos del extenso documento que la Conferencia de los obispos alemanes envió a la Comisión antepreparatoria del Concilio, en abril de 1960, con sus sugerencias sobre los temas a tratar en la reunión conciliar (Acta et Documenta, 760).

7. La presencia destacada del ambón para la proclamación de las lecturas.

8. La disposición de un lugar definido para el coro.

9. El lugar para los fieles, con bancos o sillas.

10. La reverencia y espacio de honor para la fuente bautismal, que podría situarse en un espacio celebrativo propio.

11. El lugar visible para los confesionarios.

12. El impulso a la colocación de imágenes sagradas, recomendando especialmente para el santuario las que representan los misterios de la vida de Cristo, y advirtiendo la inconveniencia de su multiplicación, reprobando muy particularmente esta práctica para las que se sitúan tras el altar.

13. El orden en la decoración, que debería buscar el equilibrio entre la función iconográfica y la ornamental, entre la figuración y la abstracción.

14. Finalmente, la preferencia de los motivos cristianos para el arte funerario (Lameri 2013, 820-833).

Como se ve, nos encontramos ante todo un completo y audaz programa de ordenación del espacio celebrativo.

\section{EL CONCILIO VATICANO II: SACROSANCTUM CONCILIUM Y PRESBYTERORUM ORDINIS}

Consideramos que son tres los textos esenciales de los documentos del Concilio Vaticano II que tratan directamente el argumento de la arquitectura sagrada: los nn. 124 y 128 de SC y el n. 5 de Presbyterorum Ordinis (en adelante PO). Comenzamos por SC 128, que trata sobre la reforma de la arquitectura sagrada (Gil Hellín 2003, 388-391).

«Revísense cuanto antes, junto con los libros litúrgicos, de acuerdo con el artículo 25, los cánones y prescripciones eclesiásticas que se refieren a la disposición de las cosas externas del culto sagrado, sobre todo en lo referente a la apta y digna edificación de los templos, a la forma y construcción de los altares, a la nobleza, colocación y seguridad del sagrario, así como también a la funcionalidad y dignidad del baptisterio, al orden conveniente de las imágenes sagradas, de la decoración y del ornato. Corríjase o suprímase lo que parezca ser menos conforme con la Liturgia reformada y consérvese o introdúzcase lo que la favorezca» ${ }^{1}$.

Acabamos de referirnos a la Declaratio de catorce puntos que acompañaba el borrador de este n. 128. Dichas propuestas provocaron muchas intervenciones por parte de los Padres conciliares, que revelaron la dificultad para materializar esta reforma (Gil Hellín 2003, 391). Algunos de ellos se mostraron favorables a que el texto de la constitución diera directrices más concretas en este ámbito (Gil Hellín 2003, 947). Fue voluntad del Concilio, sin embargo, que los detalles particulares sobre la reforma de la arquitectura cristiana y de sus lugares celebrativos quedaran reservados - dada la complejidad del argumento- al trabajo de las comisiones postconciliares (Gil Hellín 2003, 391). Una nota que acompañaba el primer párrafo de SC 


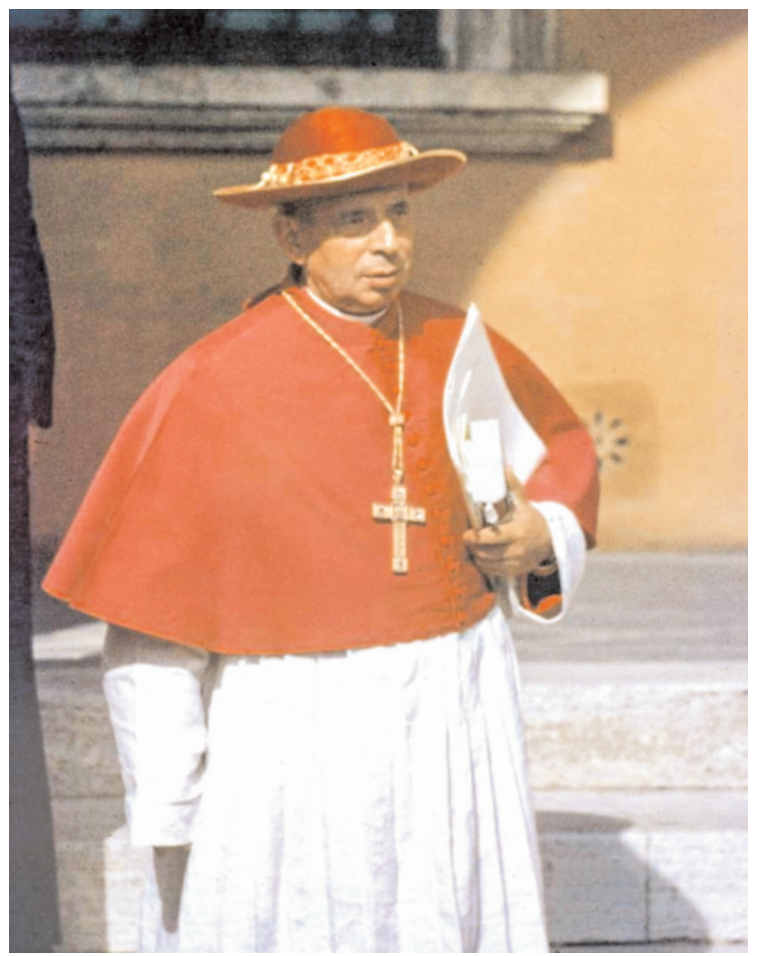

Fig. 03. El cardenal Giacomo Lercaro (1891/1976), en 1958.

128, modificado tras las emendationes de los Padres al contenido propuesto por la Commissio, reconoce que la Declaratio era incierta, y que la materialización de este artículo era una cuestión dificilísima². Los Padres pues, conociendo las propuestas concretas de la Declaratio, decidieron no incluirlas.

El análisis del iter redaccional de SC 128 revela, por un lado, que entre los Padres conciliares había un gran consenso sobre la necesidad de reformar la arquitectura sagrada - la forma de los templos, los altares, el sagrario, el bautisterio, el programa iconográfico y el ornato- , aunque no existía unanimidad sobre el modo concreto de ejecutar dicha reforma. Esta debería hacerse al ritmo de la renovación de los libros litúrgicos (Gil Hellín 2003, 391). El debate sobre las propuestas de la Declaratio provocó, precisamente, que se añadiera al primer párrafo de este número 128 la precisación de que la reforma posterior debería hacerse «una cum libris liturgicis ad normam art. 25 quam primum».

Otros textos importantes sobre la arquitectura litúrgica son el primer y el tercer párrafo de SC 124: «(124/1) Los ordinarios, al promover y favorecer un arte auténticamente sacro, busquen más una noble belleza que la mera suntuosidad. Esto se ha de aplicar también a las vestiduras y ornamentación sagrada. [...] (124/3) Al edificar los templos, procúrese con diligencia que sean aptos para la celebración de las acciones litúrgicas y para conseguir la participación activa de los fieles»». Y SC 124/2 dice: «Procuren cuidadosamente los Obispos que sean excluidas de los templos y demás lugares sagrados aquellas obras artísticas que repugnen a la fe, a las costumbres y a la piedad cristiana y ofendan el sentido auténticamente religioso, ya sea por la depravación de las formas, ya sea por la insuficiencia, la mediocridad o la falsedad del arte».

Este punto 124 presenta tres principios generales aplicables a la arquitectura sagrada: el principio de funcionalidad litúrgica; el de la participación activa de los fieles; y el de la búsqueda de la noble belleza, más que la mera suntuosidad (potius nobilem intendant pulchritudinem quam meram sumptuositatem).

Por otra parte, SC 125 subrayará la importancia de exponer imágenes sagradas para la devoción de los fieles, si bien limitadas en su número y según un orden. Este punto fue añadido por los Padres conciliares, ya que no estaba en el borrador entregado por la Commissio (Gil Hellín 2003, 382-383).

En el iter de la redacción de SC 124/3, un apunte que acompaña al texto añade lacónicamente que este párrafo, aparecido en la segunda redacción de la constitución litúrgica aprobada por los Padres, fue añadido «iuxta mentem Em.mi Lercaro» (Gil Hellín 2003, 381) (Fig. 03). Unas palabras del cardenal Lercaro, tomadas de una conferencia de 1959 (discurso al inaugurarse en Colonia la Exposición de Arquitectura Religiosa de Italia), apenas tres años antes de que se redactara esta frase, nos pueden ayudar a precisar la mens del Padre conciliar a este respecto: «La liturgia dice al artista que la obra para cuya creación se le llama es ciertamente la casa del Señor [...] La iglesia no es, o mejor dicho, no es primera y principalmente, el lugar destinado al encuentro individual, íntimo, del espíritu con Dios; aunque, siendo este encuentro una legítima exigencia, la iglesia debiera ser un lugar favorable a él» (Plazaola 2006, 651). 
Así pues, la iglesia descrita por Lercaro se forma desde la acción celebrativa. En ella hay espacio tanto para el rito comunitario como para la oración personal.

En cualquier caso, las intervenciones del cardenal Giacomo Lercaro (1891/1976) —arzobispo de Bolonia y posteriormente presidente del Consilium para la actuación de la reforma litúrgica (1964/67) — a lo largo del proceso de redacción del texto no permiten desvelar con exactitud la mens del Padre conciliar respecto al doble criterio sobre la idoneidad de los templos «ad liturgicas actiones exsequendas et ad fidelium actuosam participationem obtinendam».

Por último, el decreto PO del Concilio Vaticano II sobre el ministerio y vida de los presbíteros (1965), dedica en su número 5 unas importantes palabras al templo cristiano (Gil Hellín 1996, 64-67): «La casa de oración en que se celebra y se guarda la Sagrada Eucaristía, y se reúnen los fieles, y en la que se adora para auxilio y solaz de los fieles la presencia del Hijo de Dios, nuestro Salvador, ofrecido por nosotros en el ara sacrificial, debe de estar limpia y dispuesta para la oración y para las funciones sagradas ${ }^{4}$. En ella son invitados los pastores y los fieles a responder con gratitud a la dádiva de quien por su Humanidad infunde continuamente la vida divina en los miembros de su Cuerpo» ${ }^{5}$.

La imagen utilizada para designar la iglesia-edificio - que habla no tanto de su arquitectura sino de su naturaleza y programa de usos- es la de «casa de oración». Se insiste en el principio de la funcionalidad litúrgica para el edificio sagrado, enriqueciendo esta perspectiva con la de la adecuación para la oración. El panorama que estas breves palabras nos hacen de la iglesia es rico y se estructura a partir de tres binomios: celebración y reserva eucarística; adoración y ofrecimiento del sacrificio; oración y acciones sagradas. Esta última distinción hace referencia al papel destacado que la piedad extralitúrgica juega en el templo. Dicha hipótesis se verifica estudiando el iter redaccional del texto, que explicita la intención o mens de los Padres conciliares (Gil Hellín 1996, 64-67).

La segunda etapa del iter redaccional de PO muestra que los Padres pretendían especificar que la referencia inicial a la «oración» (domus orationis) aludía tanto a la oración mental como a la vocal, tanto a la litúrgica como a la no ritual (Gil Hellín 1996, 649). Por otro lado, la referencia a la Eucaristía celebrada junto a la reservada al inicio de la primera frase fue una preci- sación en la segunda fase de este iter («Sanctissima Eucharistia celebratur et servatur»), como lo fue también la referencia a la adoración de las especies eucarísticas durante la cuarta fase («[praesentia] Filii Dei Salvatoris nostri in ara sacrificali pro nobis oblati, in auxilium atque solatium fidelium colitur»). Este último matiz fue requerido por muchos Padres, «para que no pareciera que el culto eucarístico se reduce al sacrificio eucarístico» («ne videatur cultum Eucharisticum coarctari ad Sacrificium Eucharisticum») (Gil Hellín 1996, 66).

Las precisiones del decreto $\mathrm{PO}$, apoyándose en el texto de SC, de algún modo amplían - especificándola - la general referencia a la adecuación de la iglesia a las ceremonias litúrgicas y a la participación activa de los fieles, de las que habla la constitución litúrgica (SC 124/3).

\section{LAS INSTRUCCIONES INTER OECUMENICI (1964) Y EUCHARISTICUM MYSTERIUM (1967) Y LA INSTITUTIO GENERALIS MISSALIS ROMANI (1969)}

Como hemos visto, el Concilio no deseó dar indicaciones concretas sobre el modo de construir iglesias, de ordenar sus espacios celebrativos o de erigir los altares. En cambio, éstas fueron dadas por la Congregación de Ritos a través del Consilium (Fig. 04), encargado de la actuación de la reforma litúrgica en los años sucesivos a la publicación de la constitución SC —adelantándose a la reforma de los libros litúrgicos y contraviniendo así lo que había indicado el Concilio-, especialmente a través de dos instrucciones: Inter Oecumenici (1964) y Eucharisticum Mysterium (1967).

La primera de ellas dedica todo su último capítulo (n $\left.{ }^{\circ} 90-99\right)$ a la erección de iglesias y altares «ad fidelium actuosam participationem facilium obtinendam». A lo largo de sus diez puntos, se dan criterios concretos para la disposición general del templo y para el lugar de los fieles, así como para los lugares litúrgicos de la iglesia (ara, sede, ambón, bautisterio). En las disposiciones se sanciona el criterio de la autonomía espacial del altar para la celebración versus populum $\left(\mathrm{n}^{\mathrm{0}} 91\right)$. El texto latino de estos diez puntos recuerda el de la Declaratio en el modo de redactarse y en las expresiones utilizadas (Kaczynski 1976, 50-78).

Eucharisticum Mysterium trata - por lo que respecta al espacio celebrativo- del sagrario en la iglesia $\left(\mathrm{n}^{\circ}\right.$ 


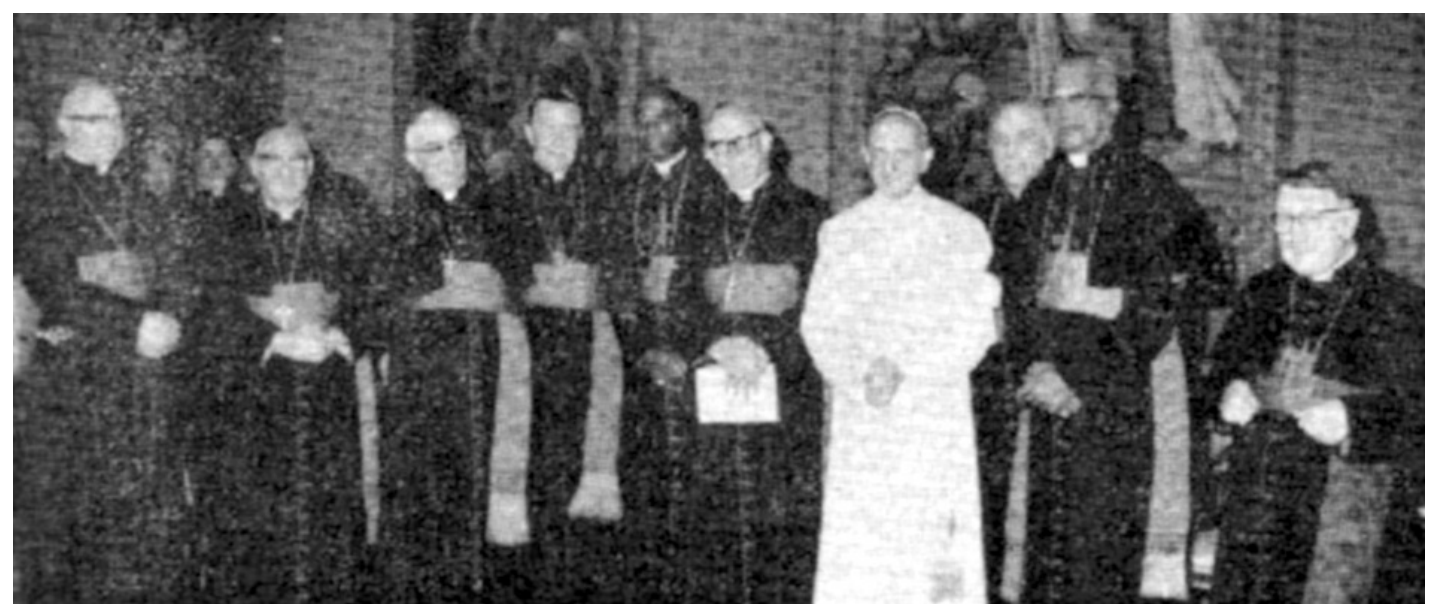

Fig. 04. Pablo VI con algunos miembros del Consilium para la actuación de la reforma litúrgica, 10 de abril de 1970.

52-57). Recomienda la edificación de la capilla del Santísimo independiente de la nave de la iglesia ( $\left.\mathrm{n}^{\circ} 55\right)$ y la separación material del altar y del sagrario «ratione signi» (por razón del signo, $\mathrm{n}^{\circ}$ 55) (Kaczynski 1976, 320-351).

Ambas instrucciones son, junto con la misma Sacrosanctum Concilium, los documentos más citados en el capítulo V de la Institutio Generalis Missalis Romani (la introducción teológico-pastoral para el uso del misal), dedicado a la disposición y ornato de las iglesias. El cambio generalizado en el modo de construir las iglesias y de disponer sus espacios celebrativos en el mundo católico se producirá a partir de la publicación en 1969 de este Misal de Pablo VI.

\section{CONCLUSIONES}

Se podría decir que el Concilio Vaticano II ha influido en la arquitectura cristiana de dos modos: uno directo y otro indirecto. Por modo directo entendemos el apremiante e indeterminado deseo de reforma de la arquitectura eclesial y sus elementos (SC 128). Los tres criterios que deberían guiar el diseño de los nuevos templos cristianos eran la funcionalidad litúrgica, la potenciación de la participación activa de los fieles y el fomento de la noble belleza (SC 124). Para realizar tan laudable tarea, era necesario considerar la plurifuncionalidad del espacio sagrado: acciones litúrgicas y devo- ción; celebración y reserva eucarística; oración dentro y fuera de los ritos (PO 5). Estos breves pero vigorosos trazos dibujan la «iglesia según el Concilio Vaticano II» que desearon los Padres conciliares con el Papa.

Junto a esta influencia directa del Concilio en arquitectura, existe también una influencia indirecta no menos importante, que nace de la interpretación constructiva de algunos principios teológicos - especialmente eclesiológicos y litúrgicos - de los documentos conciliares. El fuerte valor simbólico del edificio eclesial como imagen de la Iglesia, tan tradicional en la historia cristiana, hacía del templo postconciliar un medio privilegiado para expresar, por ejemplo, la naturaleza jerárquica y carismática de la Iglesia que emerge de la constitución Lumen Gentium (passim), o la imagen que la Iglesia ofrece al mundo según Gaudium et Spes 40.

También admitirían — análogamente - una interpretación constructiva la veneración de la Palabra de Dios, que los fieles reciben en la «mesa de la Palabra», en expresión de Dei Verbum 21; el ejercicio del sacerdocio de Cristo en la asamblea litúrgica según Sacrosanctum Concilium 7 o la centralidad de la Eucaristía en la Iglesia según Presbyterorum Ordinis 5. Pero la exposición detallada de estas consideraciones excede el objetivo de esta comunicación. 


\section{NOTAS}

(1) «Canones et statuta ecclesiastica, quae rerum externarum ad sacrum cultum pertinentium apparatum spectant, praesertim quoad aedium sacrarum dignam et aptam constructionem, altarium formam et aedificationem, tabernaculi eucharistici nobilitatem, dispositionem et securitatem, baptisterii convenientiam et honorem, necnon congruentem sacrarum imaginum, decorationis et ornatus rationem, una cum libris liturgicis ad normam art. 25 quam primum recognoscantur: quae liturgiae instauratae minus congruere videntur, emendentur aut aboleantur; quae vero ipsi favent, retineantur vel introducantur»».

(2) «Fatendum est textum huius articuli, seiunctum a Declaratione a Commissione Praeparatoria eidem anexa, quadam incertitudine laborare. Quaestio difficillima est de concreta executione huius art.».

(3) «Curent Ordinarii ut artem vere sacram promoventes eique faventes, potius nobilem intendant pulchritudinem quam meram sumptuositatem. Quod etiam intellegatur de sacris vestibus et ornamentis. (...) In aedificandis vero sacris aedibus, diligenter curetur ut ad liturgicas actiones exsequendas et ad fidelium actuosam participationem obtinendam idoneae sint».

(4) Al final de la primera frase se añade una nota a pie donde se citan los nn. 122-127 de SC, dedicados al arte litúrgico.

(5) «Domus orationis in qua Sanctissima Eucharistia celebratur et servatur, fidelesque congregantur, et in qua praesentia Filii Dei Salvatoris nostri in ara sacrificali pro nobis oblati, in auxilium atque solatium fidelium colitur, nitida, orationi et sacris sollemnibus apta esse debet. In ea Pastores et fideles invitantur ut grato animo respondeant dono Ipsius, qui per Humanitatem suam continua vitam divinam in membra Corporis sui infundit». Una cita al final de la segunda frase hace referencia a la encíclica de Pablo VI Mysterium Fidei (publicada ese mismo año 1965), donde el Papa anima a los fieles a no omitir la piadosa costumbre de la visita al Santísimo Sacramento, reservado en los templos cristianos.

\section{BIBLIOGRAFÍA}

Acta et Documenta Concilio Oecumenico Vaticano II apparando. 1960. Series I Vol. II Pars I (Europa). Ciudad del Vaticano: Typis Polyglottis Vaticanis.

Gil Hellín, Francisco, ed. 1996. Decretum de presbyterorum ministerio et vita Presbyterorum Ordinis. Concilii Vaticani II synopsis 3. Ciudad del Vaticano: Libreria Editrice Vaticana.

Gil Hellín, Francisco, ed. 2003. Constitutio de Sacra Liturgia Sacrosanctum Concilium. Concilii Vaticani II synopsis 5. Ciudad del Vaticano: Libreria Editrice Vaticana.

Kaczynski, Reiner, ed. 1976. Enchiridion Documentorum Instaurationes Liturgicae. Vol. I. (1963/73). Casale Moferrato: Marietti.

Lameri, Angelo, ed. 2013. La «Pontificia Commissio de Sacra Liturgia Praeparatoria Conilii Vaticani II». Documenti, testi, verbali. Roma: CLVEdizioni Liturgiche.

Plazaola Artola, Juan 2006. Arte sacro actual. Madrid: BAC.

Ratzinger, Joseph. 2012. Presentación de Conversi ad Dominum. Zu Geschichte Und Theologie Der Christlichen Gebetsrichtung, de Uwe Michel Lang [2003]. En Cervera Barranco, Pablo y Carlos Granados García, eds. Joseph Ratzinger. Obras Completas XI. Teología de la Liturgia. Madrid: BAC, 349-351.

Verdon, Timothy. 2012. Breve storia dell'arte sacra cristiana. Brescia: Queriniana.

\section{PROCEDENCIA DE LAS ILUSTRACIONES}

Fig. 01. https://commons.wikimedia.org.

Fig. 02. https://sacramentumfuturi.wordpress.com.

Fig. 03. https://it.wikipedia.org.

Fig. 04. L'Osservatore Romano (edición semanal inglesa), 30 de abril de 1970. 